\title{
The Effects of Sinter-Hip Processing on the Machining Performance of Cemented Carbides Based on NBC-NI Systems as Alternative Cutting Tools
}

\author{
Laerte Jose Fernandes ( $\sim$ laertejf@alumni.usp.br) \\ Universidade de Sao Paulo \\ Rodrigo L. Stoeterau \\ Universidade de Sao Paulo \\ Gilmar F. Batalha \\ Universidade de Sao Paulo
}

Fábio Miranda

Universidade de Sao Paulo

Daniel Rodrigues

Universidade de Sao Paulo

\section{Research Article}

Keywords: Cemented carbide, Niobium carbide, machining, powder metallurgy, Sinter-HIP

Posted Date: August 17th, 2021

DOI: https://doi.org/10.21203/rs.3.rs-772290/v1

License: (c) (1) This work is licensed under a Creative Commons Attribution 4.0 International License.

Read Full License 


\section{Abstract}

This work aims to investigate the technical feasibility of using sintered carbides based on $\mathrm{NbC}-\mathrm{Ni}$ substitute of the WC-Co class, adding the Sinter-Hip step in the sintering process, with 20 bar pressure nitrogen gas. The samples were produced investigating two process variables: sintering cycles and chemical composition. The samples were qualified in terms of Vickers hardness, toughness and density by Archimedes. The machining experiments were carried out on quenched and tempered AISI 4340 steel material. Flank wear progression was defined as the control parameter, analyzing wear via CCD camera, stereoscopic magnifying glass and SEM/EDS. The best result obtained the binding phase content $10 \% \mathrm{w}$, when compared to a commercial WC-Co insert. It showed superior performance at $88 \%$ of the average life of the cutting edge. However, the dispersion of this lifetime was higher than the WC-Co reference tool, $15 \%$. The samples of NbC-10\%p Ni showed a higher level of porosity than WC-Co. For better densification, new samples with the same composition were produced by adding the Sinter-HIP step. New tests were carried out and the results showed that the adjustment of the sintering process was fundamental. Densification and microstructure alteration reduced the dispersion of the average lifetime of this new $\mathrm{NbC}-\mathrm{Ni}$ class.

\section{Introduction}

Niobium carbide has been used as a secondary hard phase material in high speed steels, tungsten carbide and titanium cermet tools, but its potential as a primary hard phase in cutting tools needs to be further explored. The hardness of niobium carbide is comparable to that of titanium, tungsten, molybdenum and chromium carbides [1], as shown in Fig. 1. Its high hardness offers high wear resistance, which is desirable for cutting tool applications. On the other hand, its low solubility and high sintering temperatures are the two main obstacles to be overcome. The improvement of the sintering technique makes it possible to exploit its full potential as a material for cutting tools. The process of hot compaction, high frequency induction sintering and plasma sintering (SPS) enables high quality NbCbased carbides to be obtained [1, 2].

Cutting tools are subject to enormous stresses, high temperature, high contact pressure and different wear and damage conditions during chip formation. The main desirable requirements for cutting tool materials are hardness and pressure resistance, bending strength and toughness, edge strength, internal bond strength, high temperature resistance, oxidation resistance, low diffusion and adhesion propensity, strength to abrasion and reproducible wear behavior [4].

According to Peter and Rosso [5] an effective cutting tool must have good wear resistance to be able to maintain its integrity against abrasion during service, an adequate toughness to be able to absorb the energy imposed by different loading / unloading forces and vibrations, and adequate hardness to be able to survive continuous changes in shape and geometry during cutting. 
An ideal cutting material combines high hardness with toughness and chemical stability. The problem is that hardness and toughness represent opposite properties; normally, as the hardness value increases, the toughness value decreases. As a result, there is no single cutting material which achieves all three conditions simultaneously. Therefore, the biggest challenge in the development of cutting tools is finding the balance between these three conditions $[4,6,7,8]$. The development of cutting tool materials should consider these requirements as a balanced compromise, since there is no cutting tool material that combines all the properties at their optimum level.

This work aimed to analyze the effects of the addition of the Sinter-Hip step in the manufacturing process of $\mathrm{NbC}-\mathrm{Ni}$ based cutting tools, compared to the same grade which had previously been produced in the vacuum oven plus argon, with 20 bar pressure for rapid cooling from $1420^{\circ} \mathrm{C}$ to $800^{\circ} \mathrm{C}$. These tools were compared to a WC-Co P10 commercial insert in turning tests on quenched and tempered AISI 4340 steel, hardness $320 \pm 20 \mathrm{HB}$. Flank wear progression was used as a benchmark to determine wear resistance performance.

\section{Cemented Carbides Inserts For Cuttting Tools Machining Operations}

\subsection{NbC-Ni based cemented carbide tools}

Niobium carbide $(\mathrm{NbC})$ is used as the secondary phase carbide to enhance wear resistance while improving hot hardness and limiting grain growth. However, recent research has shown that niobium carbide has tribological, physical and mechanical properties important for cutting tool applications that can be used in place of tungsten carbide, which has long been used in this application [1, 2].

Recently, special attention has been given to the use of niobium for cutting tool applications, using niobium carbide $(\mathrm{NbC})$ as the main hard phase of the cutting tool substrate. Some of the properties of niobium carbide have been compared with those of tungsten carbide. Niobium carbide has some distinct advantages over this established cutting material. However, the mechanical and particularly tribological properties of $\mathrm{NbC}$ remain largely unexplored $[1,2]$.

The reduction in the world supply of $\mathrm{W}$ and the consequent increase in the prices of $\mathrm{Co}$, which are the main elements for manufacturing the substrate for cutting tools, continue to incentivize scientific research for the development of new materials for cutting tools $[9,10]$.

Several studies are being carried out into the development of products with the addition of niobium: steels for on-shore piping for oil as well as gas pipelines that work in more extreme environments; niobium microalloyed steels for weight reduction of products; orthopedic prostheses with niobiumtitanium and titanium-niobium-zirconium alloys by additive manufacturing; cermets and niobium-based coatings for applications in tools, nickel-based superalloys and alloys for applications at high 
temperatures $[1,11,12,13,14,15]$. All these recent studies have made it possible to propose a new approach in the sintering process for the fabrication of $\mathrm{NbC}-\mathrm{Ni}$ based cutting tools.

Niobium, in recent years, has received greater attention, with regard to sustainability (environment). Niobium oxide $\left(\mathrm{Nb}_{2} \mathrm{O}_{5}\right)$ and niobium carbide $(\mathrm{NbC})$ do not present risks, or critical notifications, to the Registration, Evaluation, Authorization and Restriction of Chemical Substances Program (REACH), which is regulated by the European Union with the aim of improving the protection of human health and the environment from the risks posed by chemicals. Niobium carbide has not been constrained by any critical assessment to date. On the other hand, compositions used to obtain WC-Co powder through the reduction process, such as tungsten trioxide $\left(\mathrm{WO}_{3}\right)$ and tricobalt tetroxide $\left(\mathrm{CO}_{3} \mathrm{O}_{4}\right)$, have received several classifications due to mutagenic problems, carcinogenic toxicity by $\operatorname{REACH}[1,2,11,13]$.

\subsection{Vacuum sintering under protective gas}

The sintering process takes place under vacuum or under protective gas at the appropriate temperature for the material. A defined and reproducible sintering atmosphere without atmospheric oxygen is important. This is due to several factors, such as impurities, lack of lubricant homogenization, insufficient compaction pressure, gas removal, insufficient densification. At certain pressures and temperatures, the process gas supply during sintering with argon, hydrogen, nitrogen, methane, carbon dioxide, and others can influence the structure and chemical composition of workpieces. The sintering vacuum or under protective gas (up to $0.1 \mathrm{MPa}$ ) is suitable for a high level of densification with little or no apparent porosity [16].

\subsection{Sinter-HIP process}

According to German [17], sintering has difficulty in densifying materials that naturally resist high temperatures. Typically, the driving force for sintering comes from the surface energy associated with small particles. External pressure increases the driving force, leading to faster densification. Thus, pressure-assisted sintering is a means of densifying materials that are normally resistant to sintering.

Currently, where the high performance of advanced materials is required in engineering applications, metallic and ceramic powders must be non-porous (full density). The main hot consolidation technologies currently applied in the industry for powder consolidation are Hot Pressing (HP), Hot Isostatic Pressing (HIP), Powder Extrusion and Powder Forging [18]. In cemented carbide industries, another technique has been used commercially, called Sinter-HIP.

Sinter-HIP is a thermal consolidation method for cemented carbide in which the simultaneous application of heat and pressure ( 3 to $10 \mathrm{MPa}$ ) fully consolidates the carbide during the sintering process. Following the vacuum sintering process, argon or nitrogen gas is introduced into the furnace at the sintering temperature to further reduce porosity and ensure material quality for high-performance carbide tools and other sintered parts. It results in a product which contains little or no porosity, producing a component as close as possible to the theoretical total density [17]. 
Vacuum sintering and filling the sintering furnace with pressurized gas to aid final densification are employed in Sinter-HIP processing (a pressure-assisted sintering process). A typical cycle is shown schematically in Fig. 2.

There have been several studies comparing the vacuum sintering process with the Sinter-HIP and the HIP process for manufacturing inserts or cutting tools for Cermets based on tungsten carbide. In these works, they show an increase of up to $100 \%$ in the resistance properties and there are no "lakes" of the binding phase in the homogeneous microstructure when compared to the HIP process. These studies show that for material cutting tools, in cases with a low percentage of binder, the increase in the strength of SinterHIP alloys is higher than when the materials vacuum is sintered using the Sinter-HIP process [19].

\section{Materials And Methods}

\subsection{Development of NbC-Ni cemented carbide tools by vacuum sintering under argon}

Cutting tools of different grades of $\mathrm{NbC}-\mathrm{Ni}$ were developed by varying the percentages of mass of $\mathrm{NbC}$ and $\mathrm{Ni}$ and the sintering variables (furnace atmosphere, temperature, and threshold time). The best result obtained in the machining process was with the NbC-Ni class with a binder content ( $\mathrm{Ni}$ ) of $10 \%$ by weight - NbC-Ni_967 [20]. Table 1 presents the characteristic of the NbC-Ni_967 class: composition, hardness, fracture toughness, sintering furnace atmosphere, threshold time, sintering temperature, density, and relative density. The commercial grade WC-Co - P10 (K $\mathrm{K}_{\mathrm{IC}}: 10.3 \pm 0.1 \mathrm{MPa} \cdot \mathrm{m}^{1 / 2}$ and hardness: $1670 \pm 0.5$ $\mathrm{HV}_{30}$ ) was used as a reference in the machining tests.

Initially, the development of the NbC-Ni-based grade used the vacuum sintering cycle, but to reduce nickel losses during sintering, a dynamic argon atmosphere was introduced for the sintering cycle, as can be seen in Fig. 3. The use of argon minimized nickel evaporation and promoted a better control of the nickel content after sintering [20]. The sintering temperature and threshold time were varied for the development of insert grades based on NbC-Ni. This allowed variations in the mechanical properties of the developed cutting material classes to be obtained. With the variation of threshold time, there was a variation in the hardness of the material, decreasing mainly due to grain growth, or increasing due to the dissolution of niobium in nickel. The behavior of fracture toughness was the inverse of hardness, as with increasing hardness there is a decrease in fracture toughness. A compromise solution was reached between these two phenomena. The evolution of flank wear was selected as a control parameter to evaluate the performance of the NbC-Ni cutting tools developed in comparison with the reference WC-Co [20]. 
Table 1

Composition, hardness, fracture toughness, sintering furnace atmosphere, threshold time, sintering temperature, density, and relative density for the NbC-Ni_967 tool

\begin{tabular}{|c|c|c|c|c|c|c|}
\hline $\begin{array}{l}\text { Hardness } \\
\left(\mathrm{HV}_{30}\right)\end{array}$ & $\begin{array}{l}\mathrm{K}_{\mathrm{IC}} \\
\left(\mathrm{MPa} \cdot \mathrm{m}^{1 / 2}\right)\end{array}$ & Sinter atmosphere & $\begin{array}{l}\mathrm{T}_{\text {sinter }} \\
\left({ }^{\circ} \mathrm{C}\right)\end{array}$ & $\mathrm{t}_{\text {sinter }}(\mathrm{min})$ & $\begin{array}{l}d \\
\left(\mathrm{~g} / \mathrm{cm}^{3}\right)\end{array}$ & $\begin{array}{l}d_{r} \\
(\%)\end{array}$ \\
\hline \multirow[t]{2}{*}{$1,460 \pm 40$} & $8.9 \pm 0.4$ & Vacuum + argon & $V-1,380$ & 20 & 7.60 & 97.9 \\
\hline & & & $\mathrm{Ar}-1,420$ & & & \\
\hline
\end{tabular}

First of all, the dilatometry test was performed, using the $402 S$ Netzch equipment. A sample was produced and placed inside an alumina tube, Fig. 4 (a), and this was placed inside a furnace with a dynamic nitrogen atmosphere with a flow rate of $200 \mathrm{ml} / \mathrm{min}$. With the definition of each sintering cycle, the linear contraction measurement was carried out. Figure 4 (b) schematically shows the achievement of linear contraction using a dilatometer.

The NbC-Ni alloy started to contract around $1200^{\circ} \mathrm{C}$, so the sintering could still be considered to occur in the solid state. At a temperature of $1300^{\circ} \mathrm{C}$, the alloy reached almost $15 \%$ of its linear contraction, for a 60 -minute stabilization. With the rapid rise from $1300^{\circ} \mathrm{C}$ to $1380^{\circ} \mathrm{C}$, the liquid sintering phase reached its contraction of approximately $20 \%$.

During heating, as seen in Fig. 4(b), the samples underwent contractions and shrinkage rates, significant changes in dimensions, due to phase melting near $1280^{\circ} \mathrm{C}$. Furthermore, the dissolution of $\mathrm{NbC}$ crystals and probably WC crystals led to pore closure and a better distribution of the Ni binding phase on the surfaces of $\mathrm{WC}$ and $\mathrm{NbC}$ particulates. This type of dilatometer uses two samples of the same material. One is the reference sample, which is dense so that the detection probe can produce physical alteration of the specimen, Fig. 4(b).

These changes provide information about the sintering mechanisms of these composites (liquid and solid phase sintering), which must be accompanied by the observation of microstructures under an optical microscope. It can be said that, in general, the higher the sintering temperature, the greater the densification, and the greater the linear and volumetric contraction of these materials. It can be said that in the shrinkage process, the sintering of the solid and liquid phase plays an important role in the densification of the samples.

\subsection{Development of $\mathrm{NbC}-\mathrm{Ni}$-based carbide tools by vacuum sintering under argon}

After all the analyses performed on the previously produced NbC-Ni classes, two new NbC-Ni samples were developed adding the Sinter-HIP step: the SH1 and SH2 classes had as reference the NbC-Ni_967 class that obtained the best performance in relation to NbC-Ni classes. The addition of the Sinter-HIP 
turning process, maintaining or improving the performance achieved in the machining tests performed in the grade NbC-Ni_967.

The sintering process consisted of two steps. The first was the same as the process performed for the NbC-Ni_967 grade and described in Table 1, vacuum sintering with argon. And the second step was the Sinter-HIP process, the parameters of which are described in Table 2.

The only change in powder preparation between the NbC-Ni_967 class in relation to the $\mathrm{SH} 1$ and $\mathrm{SH} 2$ class was the change in milling time from 0.5 hour to one hour in order to obtain a more homogeneous structure (attrition mill). All the other preparation steps remained the same. Grades SH1 and SH2 were produced at the same time and machining tests took place simultaneously for both grades.

The first sintering step, under vacuum + argon, for these new grades was the same as the NbC-Ni_967, Fig. 2. The second step, the Sinter-HIP process, was added after the first step. The cycle used in resintering Sinter-HIP is shown as Fig. 5. The main difference between cycles SH1 and SH2, shown in Fig. 5(a) and Fig. 5(b) respectively, were that for class $\mathrm{SH} 1$ after $\mathrm{N}_{2}$ injection and pressure at 20 bar the furnace was turned off, while in cycle $\mathrm{SH} 2$ the furnace was kept on for the temperature drop.

Table 2

Composition, hardness, fracture toughness, sintering furnace atmosphere, sintering temperature, density, and relative density for the SH tools - Sinter-HIP

\begin{tabular}{|llllll|}
\hline Samples & $\begin{array}{l}\text { Hardness } \\
\left(\mathrm{HV}_{\mathbf{3 0}}\right)\end{array}$ & $\begin{array}{l}\mathrm{K}_{\mathrm{IC}} \\
\left(\mathrm{MPa} \cdot \mathbf{m}^{\mathbf{1} 2}\right)\end{array}$ & $\begin{array}{l}\text { tsinter } \\
\left({ }^{\circ} \mathrm{C}\right)\end{array}$ & $\begin{array}{l}\boldsymbol{d} \\
\left(\mathbf{g} / \mathrm{cm}^{3}\right)\end{array}$ & $\begin{array}{l}\boldsymbol{d}_{\boldsymbol{r}} \\
(\%)\end{array}$ \\
\hline SinterHip1 (SH1) & $1,402 \pm 25$ & $9.2 \pm 0.3$ & 1,400 & 7.69 & 99 \\
\hline SinsteHip2 (SH2) & $1,407 \pm 29$ & $9.0 \pm 0.3$ & 1,400 & 7.73 & 99.5 \\
\hline Composition (\%wt) & $10 \% \mathrm{Ni}+12 \% \mathrm{WC}+14 \% \mathrm{TiC}+64 \% \mathrm{NbC}$ & \\
\hline Atmosphere & Vacuum + $\mathrm{N}_{2}+$ pressure: 20 bar & & \\
\hline
\end{tabular}

The development of these two new grades was based on the analysis of the machining performance, in particular the dispersion of the cutting-edge lifetime and the porosity of the $\mathrm{NbC}-\mathrm{Ni}$ samples in relation to the WC-Co reference sample. Through these analyses it was decided to manufacture the NbC-Ni_967 classes with the addition of the Sinter-HIP process (SH1 and $\mathrm{SH} 2$ ), as this class was the one which had obtained the best machining performance result when compared to the WC-Co reference sample.

The evolution of flank wear was performed using turning experiments. The end of life of the cutting edge was considered for a Flank Wear $\mathrm{V}_{\mathrm{B}}: 0.3 \mathrm{~mm}$. The experiments were carried out under the same conditions as the previous tests: cutting speed $V c: 160 \mathrm{~m} / \mathrm{min}$; feed rate $f .0 .1 \mathrm{~mm} / \mathrm{rev}$; cutting depth $\mathrm{a}_{\mathrm{p}}$ : $1.5 \mathrm{~mm}$ and cutting fluid was used [20]. The specimens were the same as the ones used in the previous 
Comparisons were also made in relation to microstructures (carbide distribution, grain size and porosity) and the plasticity of the binder, checking to see if there were changes with the addition of the Sinter-HIP process.

Porosity analysis of the different samples was performed based on Standard B276-5 (2015) Test Method for Apparent Porosity in Cemented Carbides [21]. There are three types of porosity classification in this standard:

- Type A: pores up to $10 \mu \mathrm{m}$ analyzed at $200 x$ magnification.

- Type B: pores in the range from 10 to $25 \mu \mathrm{m}$ analyzed at 100x magnification.

- Type C: classify porosity resulting from uncombined carbon analyzed with a magnification of 100 or 200x.

The characterization of the plasticity of the binder of the classes of cutting tools based on NbC-Ni and WC-Co reference were carried out using indentation tests instrumented by the Hystron triboindenter (TI950). In these tests, the load-displacement curves were obtained, as shown in Fig. 6 . The results were analyzed by specific algorithms, which provide instrumented hardness and reduced modulus of elasticity.

The experimental conditions for the characterization of Young's modulus of the materials analyzed are described in Table 3. The preparation of the instrumented indentation experiments on the samples was a function of the applied load and the test time. All indentations were performed with a Berkovich diamond indenter.

Table 3

Experimental conditions of nanoindentation tests to obtain the Youngs mod $u s a n d b \in$ ders hardness of samples

\begin{tabular}{|lllll|}
\hline $\begin{array}{l}\text { Loads } \\
(\boldsymbol{\mu N})\end{array}$ & Loading Time (s) & Creep Time (s) & Unloading Time (s) & Number of Replications \\
\hline 300 & 5 & 2 & 5 & 10 \\
\hline
\end{tabular}

Based on the reduced modulus of elasticity of the binder, it was possible to calculate the modulus of elasticity of the samples using the Oliver and Pharr equation [22].

$$
\frac{1}{E_{r}}=\frac{\left(1-\nu_{i}^{2}\right)}{E_{i}}+\frac{\left(1-\nu_{s}^{2}\right)}{E_{s}}(1)
$$

In this, $\mathrm{E}_{\mathrm{r}}$ is the reduced modulus; $\mathrm{E}_{\mathrm{i}}$, and $\mathrm{v}_{\mathrm{i}}$ and $\mathrm{E}, \mathrm{v}$ are Youngs mod $u s$ and Poissons ratio of the diamond indenter and the specimen, respectively.

Statistical analysis of all data obtained during the experiments was performed. A 95\% confidence interval Loading [MathJax]/jax/output/CommonHTML/jax.js ulated the standard deviation of each average obtained. As 
this interval can overlap in several cases, it was necessary to perform a statistical analysis to compare the means of the analyzed variables. To confirm whether there was a statistical difference between the means, an ANOVA analysis of variance was used, through the Minitab software, in order to confirm the differences between the analyzed variables, between the classes of the NbC-Ni tools and between them and the class reference of WC-Co.

\section{Analysis Of Results}

\subsection{Porosity and microstructure analysis}

Figure 7 presents the microstructures of the analyzed samples and Table 4 presents the result obtained in this analysis.

Table 4

Classification of porosity types - SH classes compared to NbC_Ni-967 and WC-Co reference classes

\begin{tabular}{|cccll|}
\hline Types & SH1 & SH2 & NbC-Ni_967 & WC-Co reference \\
\hline Type A & A4 & A4 & A6 & A2 \\
Type B & - & - & B2 & - \\
Type C & - & - & - & - \\
\hline
\end{tabular}

There was a reduction in porosity of SH classes compared to NbC_Ni-967. With the addition of Sinter-HIP there was an elimination of Type B porosity $(>10$ to $\leq 25 \mu \mathrm{m})$ and an improvement in Type A porosity (pores $\leq 10 \mu \mathrm{m}$ ), but the results are lower than the WC-Co reference class. In the analyses carried out previously, all $\mathrm{NbC}$-Ni classes, produced in vacuum sintering and vacuum sintering + argon, had presented Type B2 and B6 porosity and Type A6 porosity [21].

Classes SH1 and SH2 presented "Ni lakes", and the same had occurred for the previously developed classes, Fig. 6. The distribution of carbides (classes SH1 and SH2) remained heterogeneous, even doubling the milling time, confirmed by the distribution of tungsten in Fig. 8 (a) (b) (c), which show tungsten concentration in regions of area " $B$ ", compared to regions of area " $A$ ".

Comparing the microstructures of $\mathrm{SH} 1$ and $\mathrm{SH} 2$, it is possible to observe, in Fig. 9 (d) (e), that the grain size of the $\mathrm{SH} 2$ class carbides is smaller than that of the $\mathrm{SH} 1$ class. This could be due to the cooling time in the sintering process. Class $\mathrm{SH} 2$ had a longer cooling time, as the Sinter-Hip oven was kept on during this process, while for Class $\mathrm{SH} 1$ the oven was turned off, resulting in a greater drop in temperature during this process.

Two phenomena occurred for the differentiation of grain size between classes $\mathrm{SH} 1$ and $\mathrm{SH} 2$ : the dissolution of secondary carbides, which restricts the growth of NbC grains, and the longer time, which Loading [MathJax]/jax/output/CommonHTML/jax.js by coalescence. From the result obtained, as shown in Fig. 9 
(d) (e), the first phenomenon prevailed over the second, as the grains of $\mathrm{SH} 2$ are smaller than those of $\mathrm{SH} 1$, even with the cooling time in the sintering process of $\mathrm{SH} 1$ being shorter than that of $\mathrm{SH} 2$.

Therefore, the microstructure of SH classes, even with the reduction of porosity, remains heterogeneous compared to the WC-Co reference class.

\subsection{Binder plasticity analysis}

In previous tests [23], the class which had the lowest modulus of elasticity of the binder was WC-Co reference to 192.2 GPa, while the class NbC_Ni-967 showed the lowest elastic modulus of the Ni-NbC classes $(235.7 \mathrm{GPa}$ ). There was a variation between 235.7 and $367 \mathrm{GPa}$ of the analyzed NbC-Ni classes [23]. In relation to the hardness of the binder $(\mathrm{H})$ the $\mathrm{NbC}$-Ni classes presented a variation between 3.93 and $5.87 \mathrm{GPa}$, while in the NbC-Ni_967 class the hardness was $4.70 \mathrm{GPa}$, but statistically equal to the WCCo reference, which was $4.25 \mathrm{GPa}$ [23].

It was possible to observe that classes $\mathrm{SH} 1$ and $\mathrm{SH} 2$ had the same behavior as the analyzed parameters. The two classes produced with the addition of the Sinter-HIP process had the same statistical behavior in relation to the NbC-Ni_967 class, but the dispersion of the results of the analyzed parameters was much smaller in the SH classes when compared to the NbC-Ni_967 class, as can be seen in Table 5. This may indicate that the addition of Sinter-HIP reduced the variability of the results of the analyzed parameters.

Table 5

Average parameters obtained via nanoindentation: $\mathrm{SH}$ classes compared to NbC-Ni_967 and WC-Co reference classes

\begin{tabular}{|lllll|}
\hline Variables & SH1 & SH2 & NbC-Ni_967 & WC-Co reference \\
\hline $\mathrm{H}(\mathrm{GPa})$ & $5.03 \pm 0.18$ & $4.97 \pm 0.21$ & $4.70 \pm 0.71$ & $4.25 \pm 0.21$ \\
\hline$E(\mathrm{GPa})$ & $233.3 \pm 19.4$ & $232.0 \pm 24.6$ & $235.7 \pm 35.9$ & $192.2 \pm 16.0$ \\
\hline
\end{tabular}

With the introduction of the Sinter-HIP process, there was a reduction in the dispersion of the results of classes SH1 and SH2 in relation to class NbC_Ni-967. There was therefore a greater differentiation of results between classes SH in relation to WC-Co reference than the classes NbC_Ni-967 and WC-Co reference.

\subsection{Machining analysis}

Machining experiments were carried out with classes $\mathrm{SH} 1$ and $\mathrm{SH} 2$ under the same conditions as the previous tests. Figure 10 shows the comparative performance of each class developed in the Sinter-HIP process (SH1 and SH2) compared to the WC-Co reference and NbC-Ni_967, which was the class that had presented the best result in the machining tests previously, in terms of average lifetime of the cutting edge for a defined flank wear $\left(V_{B}=0.3 \mathrm{~mm}\right)$.

The grades sintered under vacuum and argon with the addition of the Sinte-HIP process, $\mathrm{SH} 1$ and SH2, Loading [MathJax]/jax/output/CommonHTML/jax.js is of the lifetime of the cutting edge during the machining 
process. Class $\mathrm{SH} 1$ had an average lifetime per cutting edge of $28.8 \pm 2.1$ minutes, while class $\mathrm{SH} 2 \mathrm{had}$ an average lifetime of $43.8 \pm 1.6$ minutes. Therefore, grade $\mathrm{SH} 2$ had a cutting edge lifetime greater than $\mathrm{SH} 1$ by $1.8 \mathrm{x}$.

The main difference between these classes in the manufacturing process was the cooling time in the Sinter-HIP process. Class $\mathrm{SH} 1$ had a shorter cooling time with a greater drop in temperature compared to class SH2. Due to this difference in the process, the microstructures they showed were different, and the $\mathrm{SH} 1$ had larger NbC carbide grains than the SH2 class, Fig. 9 (d) (e). Hardness and fracture toughness were also different, as described in Table 2.

Comparing the $\mathrm{SH}$ classes with the NbC-Ni_967 class, the $\mathrm{SH} 1$ class presented a $41 \%$ lower performance and the average lifetimes per cutting edge were, respectively, 28.8 and 48.9 minutes. The main difference between them was the hardness and fracture toughness; the SH1 grade had a hardness of 1,402 \pm 25 $\mathrm{HV}_{30}$ and $\mathrm{K}_{\mathrm{IC}}=9.2 \pm 0.3 \mathrm{MPa} \cdot \mathrm{m}^{1 / 2}$, while the NbC-Ni_967 grade had a hardness of $1,460 \pm 29 \mathrm{HV}_{30}$ and $\mathrm{K}_{\mathrm{IC}}=8.9 \pm 0.4 \mathrm{MPa} \cdot \mathrm{m}^{1 / 2}$. However, the lifetime dispersion of the cutting edge of $\mathrm{SH} 1$ was $8 \%$, while the $\mathrm{NbC}-\mathrm{Ni} \_967$ was $15 \%$, representing a dispersion reduction in the order of 3.5 times. The main difference between the two classes was the reduction in porosity of SH1 as shown in Table 4.

Class SH2 statistically showed equal performance to NbC-Ni_967, with 43.8 and 50.2 minutes respectively. However, there was a reduction in dispersion of 4.6 times, from $15-3.7 \%$ for the $\mathrm{SH} 2$ class. The hardness of class SH2 was lower than class NbC-Ni_967, 1,460 $\pm 29 \mathrm{HV}_{30}$ and 1,407 $\pm 29 \mathrm{HV}_{30}$ respectively. The fracture toughness was statistically equal; class SH1 was $9.0 \pm 0.3 \mathrm{MPa} \cdot \mathrm{m}^{1 / 2}$ and class NbC_Ni-967 was $8.9 \pm 0.4 \mathrm{MPa} \cdot \mathrm{m}^{1 / 2}$. However, SH2 had a lower porosity level than NbC-Ni_967 (Type A: A4; Type B: no pores and Type A: A6; Type B: B2, respectively).

Comparing WC-Co grade reference with $\mathrm{SH} 1$ class showed a statistically equal performance in the average lifetime of the cutting edge of 25.9 minutes for the WC-Co and 28.8 minutes for the $\mathrm{SH} 1$ class. However, the dispersion of WC-Co was 2.6 times lower than $\mathrm{SH} 1$ (3.2\% and 8.0\% respectively).

Class SH2 outperformed the average lifetime of the cutting edge by $68.9 \%, 43.8$ versus 25.9 minutes respectively. However, the dispersion of reference WC-Co was 3.2\% while the $\mathrm{SH} 2$ was $3.7 \%$. Therefore, with the addition of the Sinter-HIP step there was a reproducibility in the wear behavior. $\mathrm{SH} 2 \mathrm{had}$ a dispersion 1.15 times higher than WC-Co reference and 75.5\% lower than NbC-Ni_967while the NbCNi_967 class had a dispersion 4 times higher than the WC-Co reference as can be seen in Fig. 11 (a)(b)(c).

Comparisons were made between the relative SH-Ni_967 NbC and WC-Co benchmark for the wear mechanisms that acted during the turning process, shown in Fig. 12.

Class $\mathrm{SH} 1$ showed more regular abrasive wear on the cutting edge on the main face compared to $\mathrm{NbC}$ Ni_967. This could be due to the porosity reduction with the addition of the Sinter-HIP process in the SH1 class. Grade SH1 had less spalling on the edge of the edge. These spalls were due to adhesive wear that Loading [MathJax]/jax/output/CommonHTML/jax.js /e wear caused more damage in the NbC-Ni class than in the 
WC-Co class because for this system the physicochemical interactions between carbides and binder are different and the microstructure analysis showed that there is greater contiguity in the $\mathrm{NbC}-\mathrm{Ni}$ classes than the WC-Co reference class.

Comparisons between the $\mathrm{SH} 1$ and $\mathrm{SH} 2$ grades with the WC-Co reference grade, with the addition of the Sinter-HIP process, show there was a reduction in adhesion wear mechanisms and a better uniformity of abrasion wear. However, compared with the WC-Co reference class, the abrasion is not as uniform as can be seen in Fig. 10. This may be due to the fact that the WC-Co reference class presents a more homogeneous microstructure than the $\mathrm{SH}$ classes. The $\mathrm{SH}$ classes have a lot of contiguity and a heterogeneous distribution of carbides.

However, regarding the adhesion mechanism, which is the main cause of spalling of the cutting edge, the $\mathrm{SH} 2$ class presented damage very similar to the $\mathrm{WC}$-Co reference. While in the $\mathrm{SH} 1$ class the damage presented was greater than the reference class, there was less damage than the NbC-Ni_967 class, demonstrating that the addition of the Sinter-HIP process reduced the effect of the adhesion mechanism and left the abrasion wear more uniform.

\section{Conclusions}

The experiments carried out in this work aimed to evaluate the development of material grades based on $\mathrm{NbC-Ni,} \mathrm{produced} \mathrm{by} \mathrm{powder} \mathrm{metallurgy,} \mathrm{for} \mathrm{application} \mathrm{in} \mathrm{cutting} \mathrm{tools} \mathrm{for} \mathrm{machining,} \mathrm{as} \mathrm{an} \mathrm{alternative} \mathrm{to}$ the traditional WC-Co. The performance of these tools, taking into consideration wear mechanisms and edge lifetime, was evaluated based on the process-structure-properties triad.

Considering its experimental context, the work allows us to present the following conclusions:

- With the addition of the Sinter-HIP process in the grades that were produced under vacuum and argon, there was a reduction in the dispersion in the life of the cutting edge compared to the $\mathrm{NbC}-\mathrm{Ni}$ grades, which indicates that the Sinter-HIP process improved the microstructure and reduced porosity, presenting a less heterogeneous microstructure.

- The density of the grade that obtained the best machining performance, NbC-Ni_967, was 7.60 $\mathrm{g} / \mathrm{cm}^{3}$. With the addition of the Sinter-Hip step for the manufacture of $\mathrm{SH} 1$ and $\mathrm{SH} 2$ classes, based on the NbC_Ni-967 class, there was greater densification, with the density for $\mathrm{SH} 1$ rising to 7.69 $\mathrm{g} / \mathrm{cm}^{3}$ and to $7.73 \mathrm{~g} / \mathrm{cm}^{3}$ for $\mathrm{SH} 2$.

- The NbC-Ni classes with the addition of the Sinter-HIP process did not present Type B porosity, but presented Type A4 porosity instead. Without the use of Sinter-HIP, the porosity ranged from Type B2 to $\mathrm{B} 6$ and from Type A4 to A6.

- The adhesion wear mechanism was significantly reduced with the addition of the Sinter-HIP step in the sintering process.

- The SH2 grade presented an adhesion level very similar to the WC-Co reference, which may mean Loading [MathJax]/jax/output/CommonHTML/jax.js f the carbides with the binder had improved with the addition 
of the Sinter-Hip process.

- Classes SH1 and SH2 have the same composition as class NbC-Ni_967. However, the results obtained in the nanoindentations were statistically equal (hardness and Young`s Modulus), but with a significant reduction in the dispersion of the analyzed parameters due to the insertion of the SinterHIP process.

- The hardness of the binder in the NbC-Ni and WC-Co grades was statically equal.

- The NbC-Ni grades with the lowest Young`s Modulus, $232 \mathrm{GPa}$, had the best machining performance in terms of the average life of the cutting edge (NbC_Ni-967 and SH2);

- The Young 's modulus and the hardness of the binder of the SH classes were statistically equal to those of the NbC-Ni_967 class. However, class SH1 had a cutting edge average life $44 \%$ shorter than NbC-Ni_967, while class SH2 was statistically equal to NbC-Ni_967. What differentiates SH1 and SH2 is the grain size between the two classes, with the microstructure of $\mathrm{SH} 1$ being coarser than that of $\mathrm{SH} 2$.

- All NbC-Ni classes presented "Nickel lakes", regardless of the sintering process.

- The best combination of fracture toughness and hardness, considering the average life of the cutting edge, was:

- $\mathrm{K}_{\mathrm{IC}}: 8.9$ to $9.2 \mathrm{MPa} \cdot \mathrm{m}^{1 / 2}$

- Hardness: 1405 to $1460 \mathrm{HV}_{30}$

- Grades with the addition of the Sinter-HIP process have a lower dispersion of the cutting edge lifetime, however they continue to be larger than the reference WC-Co, with $\mathrm{SH} 1$ being 2.5 times larger and SH2 1.15 times larger. This is probably due to lower porosity and a more homogeneous microstructure of WC-Co.

- Even with a greater dispersion of the lifetime of the cutting edge, the classes NbC-Ni_967 and SH2 had a higher average lifetime, about 1.8 times in relation to the reference WC-Co.

Better performance and lifetime repeatability in a cutting tool are the main goals to be achieved in materials for this purpose. Research will continue to be carried out to obtain a homogeneous microstructure.

\section{Declarations}

\section{Confirmation of Authorship}

As corresponding author, I Laerte José Fernandes, hereby confirm on behalf of all authors that:

1. The authors have obtained the necessary authority for publication.

2. The paper has not been published previously, that it is not under consideration for publication elsewhere, and that if accepted it will not be published elsewhere in the same form, in English or in consent of the publisher. 
3. The paper does not contain material which has been published previously, by the current authors or by others, of which the source is not explicitly cited in the paper.

Upon acceptance of an article by the journal, the author(s) will be asked to transfer the copyright of the article to the publisher. This transfer will ensure the widest possible dissemination of information.

Funding: All resources were owned by the donation of some materials by the company Brats and EHT Consultoria (carbide and the use of equipment for the development of the work).

Conflicts of interest/Competing interests: there are no conflicts of interest in this work.

\section{References}

1. Woydt M, Mohrbacher H, Vleugels J, Huang SG (2016) Niobium carbide for wear protection - tailoring its properties by processing and stoichiometry. Metal Powder Report, V.1, n 4, p.265-272

2. Woydt M, Mohrbacher $H$ (2014) The tribological and mechanical properties of niobium carbides $(\mathrm{NbC})$ bonded with cobalt or Fe3Al. Wear 321:1-7

3. Information on https://www.niobelcon.com/NiobelCon/niobium/niobium_carbide/ acessed 18th July 2021

4. Klocke F (2011) Manufacturing processes 1: cutting. Springer, Berlin

5. Peter, I., Rosso, M., (2017). Manufacturing, Composition, Properties and Application of Sintered Hard Metals. DOI: 10.5772/66872. Disponível em: <https://www.intechopen.com/books/powdermetallurgy-fundamentals-and-case-studies/manufacturing-composition-properties-and-applicationof-sintered-hard-metals> accessed 15 July 2021.

6. Trent E, Wright $P$ (2000) Metal cutting, 4th edn. Butterworth-Heinemann, Oxford

7. Tschatsch $H$ (2009) Applied machining technology. Springer, London

8. Byrne G, Dornfeld D, Denkena B (2003) Advancing cutting technology. CIRP Ann 52(2):483-507

9. Garcia J, Ciprés VC, Blomqvist A, Kaplan B (2019) Cemented carbide microstructures: a review. Int J Refract Metal Hard Mater 80:40-68

10. Miranda F, Fernandes LJ, Batalha MHF, Rodrigues D, Stoeterau RL, Batalha GF (2021) Critical raw materials in cutting tools for machining applications - a review. Brazilian Journal of Development, 7, n.5 49513-49537. https://www.brazilianjournals.com/index.php/BRJD/issue/view/130

11. Franco E, Costa CE, Tsipas SA, Gordo E (2015) Cermets based on FeAl-NbC from composite powders: Design of composition and processing. Int. Journal of Refractory Metals and Hard Materials 48, pp.324-332, 2015

12. Vasconcelos, Y., (2019). O polêmico nióbio. Disponível em: <https://revistapesquisa.fapesp.br/2019/03/14/o-polemico-niobio/> accessed 15 July 2021.

13. Uhlmann U, Hinzmann D, Kropidlowksi K, Meier P, Prasol L, Woydt M (2018) Increased tool Loading [MathJax]/jax/output/CommonHTML/jax.js 


\section{Conference on High Performance Cutting}

14. Huang SG, Mohrbacher H, Woydt M, Vleugels J (2017) Effect of carbon content on the microstructure and mechanical properties of NbC-Ni based cermets. 19th Plansee Seminar, Austria

15. Huang SG, Vleugels J, Mohrbacher H, Woyd M (2016) Microstructure and mechanical properties of NbC matrix cermets using Ni containing metal binder. Metal Powder Report, v.71, n.5, September/October

16. Lamin JD, de Oliuveira HCP, Batista AC, Guimarães RS, Figueira M (2010) Use of Ti in hard metal alloys - Part I: structural and microstructural analysis. Materials Science \& Engineering Technology. Volume 41, Issue 4, p.198-201, April

17. German RM (2014) Sintering from empirical observations to scientific principles. Butterworth Elsevier Ed.1

18. Bose A, Animesh WB (2003) Hot Consolidation of Powders \& Particulates. Metal Powder Industries Federation, Princeton

19. Missol W, Karwata T, Krajzel J, Bujok J (1998) Comparison of the properties of ultrafine and conventional hardmetals. Proceedings of the 1998. Powder Metallurgy World Congress and Exhibition, Spain, Vol.4, 152-157

20. Fernandes LJ, Stoeterau RL, Batalha GF et al (2020) Influence of sintering condition on the tool wear of NbC-based Ni binder-cemented carbide cutting tools. International Journal Advanced Manufacturing Technology 106:3575-3585. https://doi.org/10.1007/s00170-019-04838-0

21. ASTM International - American Society for Testing and Materials (2015) Standard Test Method for Apparent Porosity in Cemented. B276-05

22. Oliver WC, Pharr GM (2004) Measurement of hardness and elastic modulus by instrumented indentation: Advances in understanding and refinements to methodology. Journal of Materials Research, v.19, n.1, Jan

23. Fernandes LJ (2021) Ferramentas de corte a base de carbonetos cimentados (metais duros) aplicadas ao torneamento de aço AISI 4340 endurecido: contribuição ao estudo de substituição ao sistema WC-Co por uma alternativa NbC-Ni (Cemented carbide cutting tools used for turning hardened AISI 4340 steel: contribution to the study of substitution of WC-Co system by a NbC-Ni alternative system). Tese de Doutorado (Doctoral thesis), Escola Politécnica, Universidade de São Paulo, São Paulo - Brazil. doi:10.11606/T.3.2021.tde-16072021-141142. Recuperado em 2021-07-20, de www.teses.usp.br

\section{Figures}




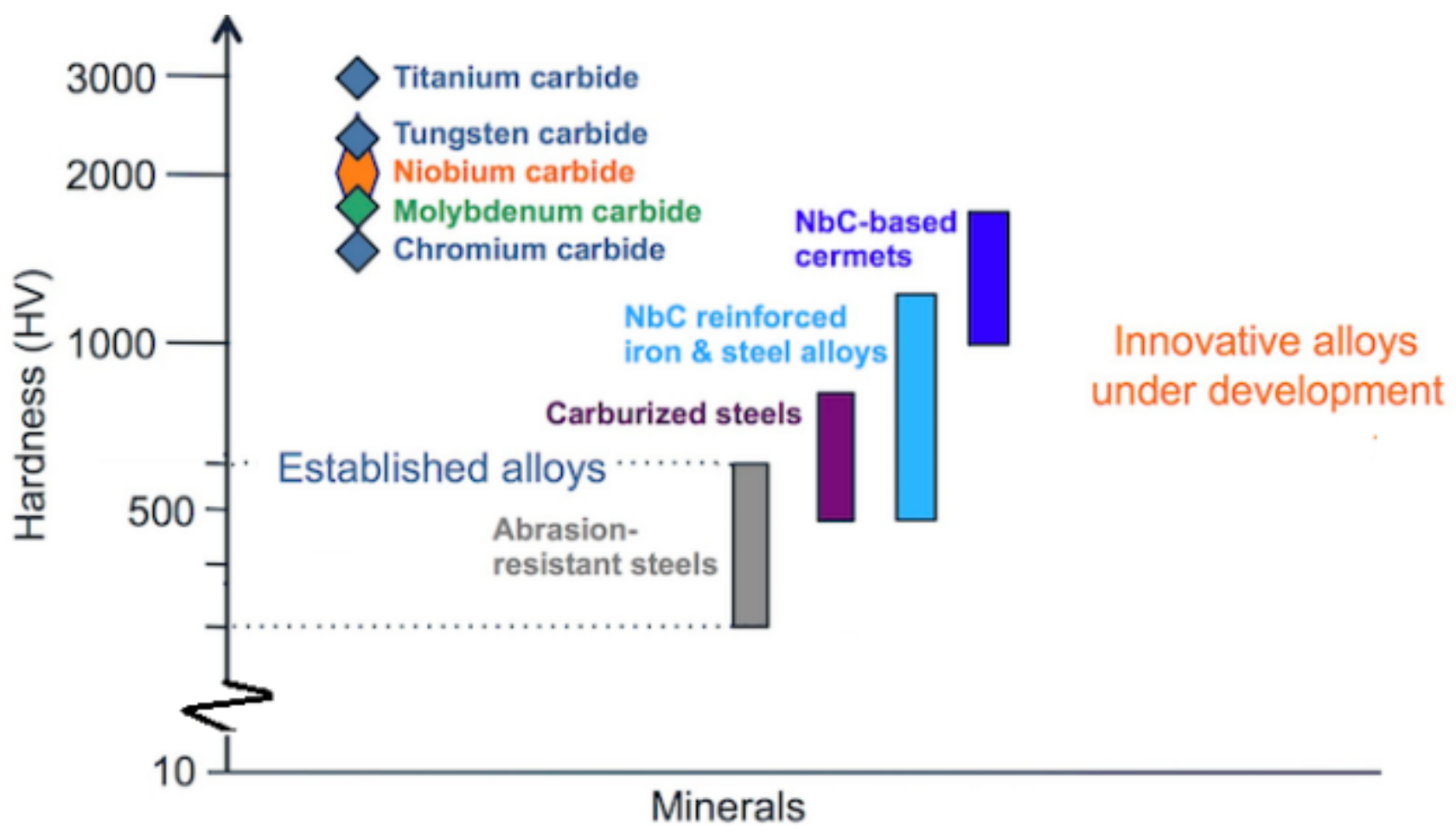

\section{Figure 1}

Comparison between Niobium carbide hardness and Titanium, Tungsten, Molybdenum and Chromium carbide [3]

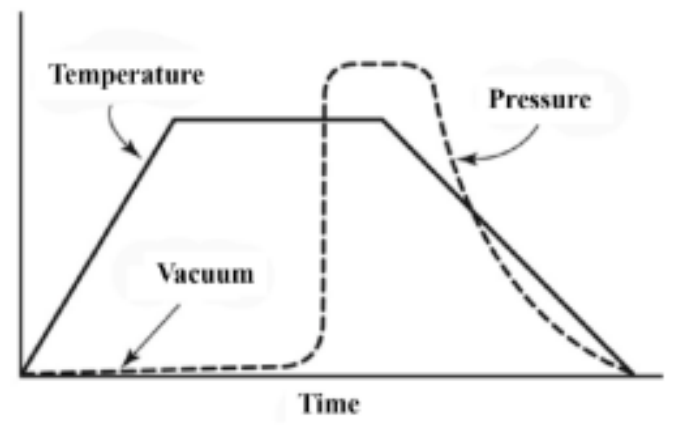

Figure 2

Schematic diagram of the pressure-assisted sintering process cycle [17] 


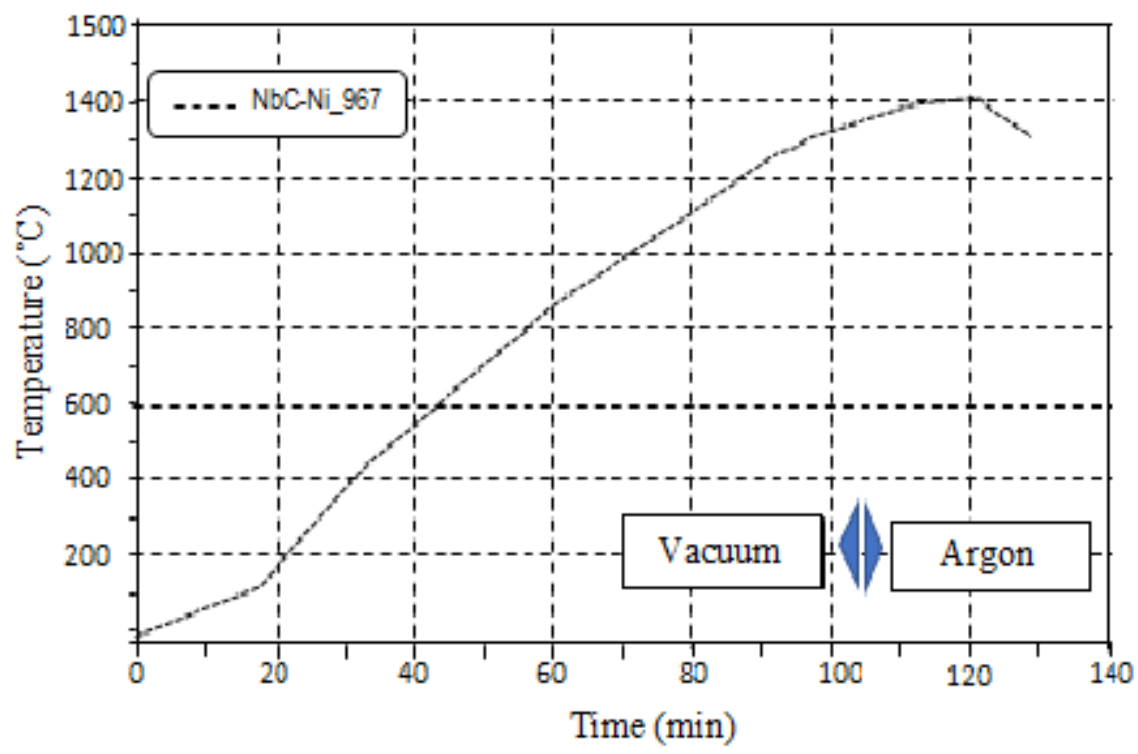

\section{Figure 3}

Sintering process with dynamic inert gas of the NbC-Ni_967 grade
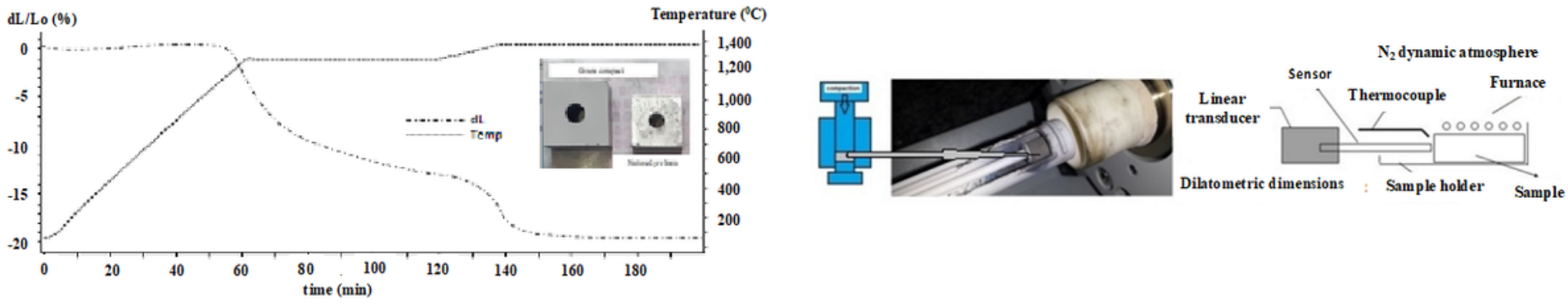

(a)

(b)

\section{Figure 4}

(a) Example of a dilatometric curve (b) Linear contraction measurement scheme to obtain the dilatometric curve
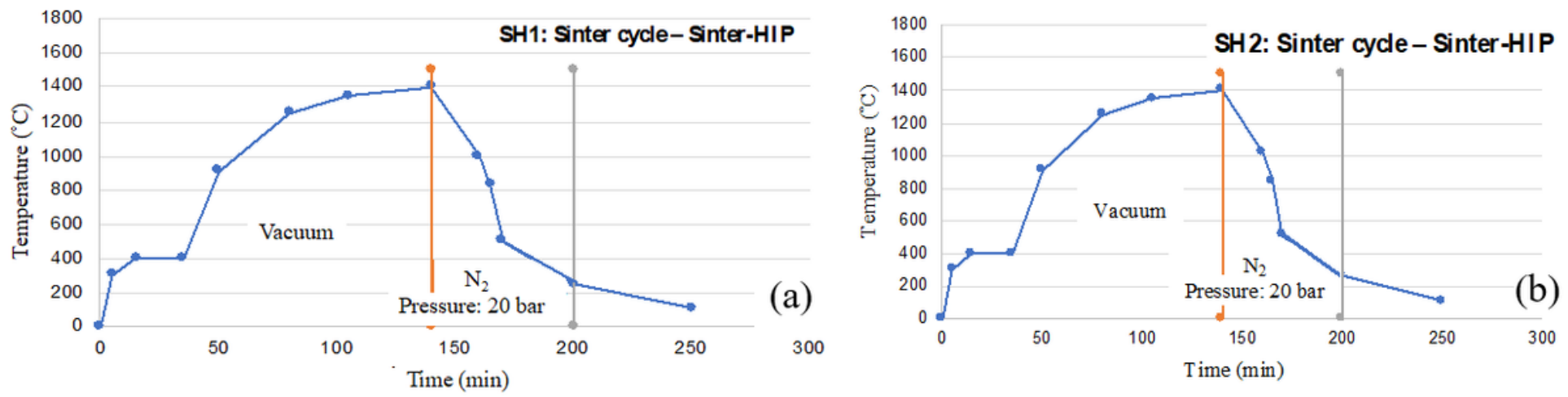

Figure 5 

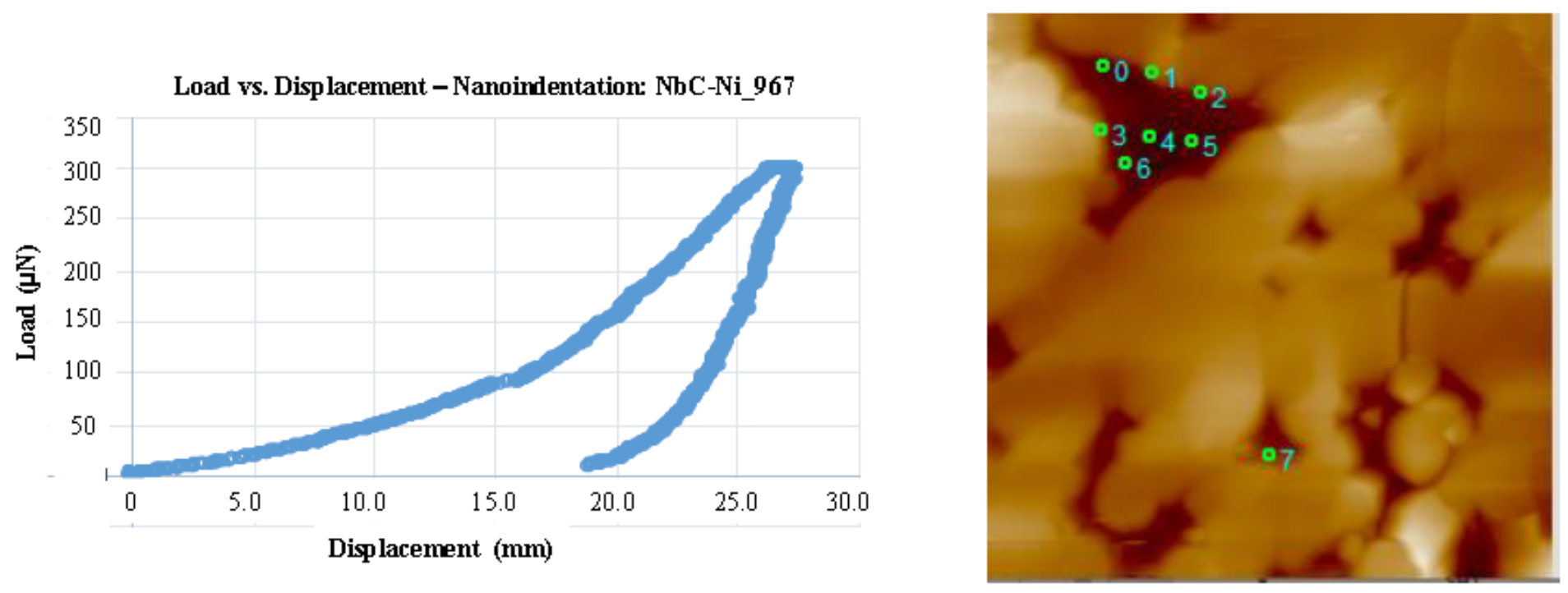

Figure 6

Example of the force-displacement curve and nanoindentation in the binder.

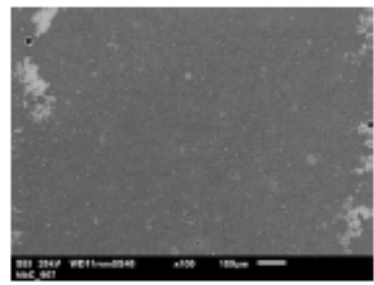

(a) HbC-Hi_967: 100x

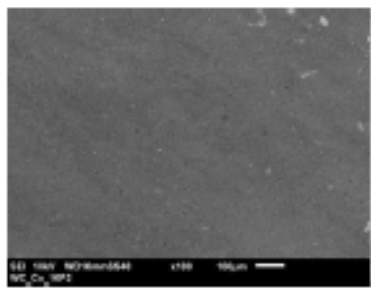

(c) WC- Co reference : $100 \mathrm{x}$

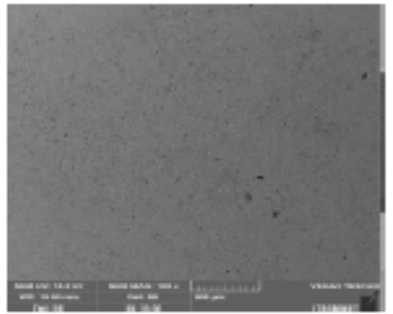

(e) $\mathrm{SH} 1: 100 \mathrm{x}$

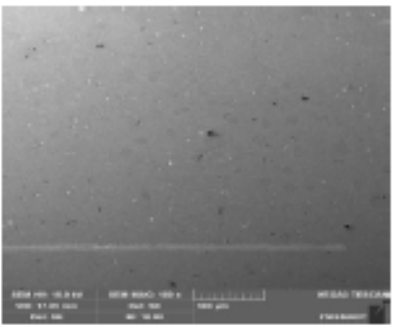

(g) SH2: $100 \mathrm{x}$

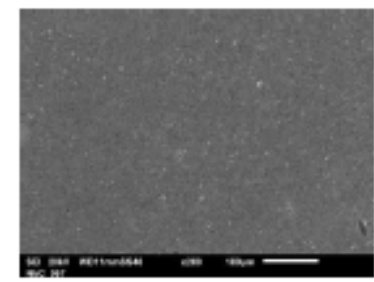

(b) HbC Hi_967:200x

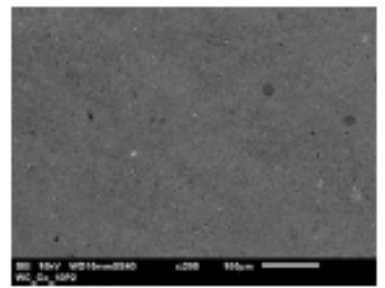

(d) WC- Co reference : $200 \mathrm{x}$

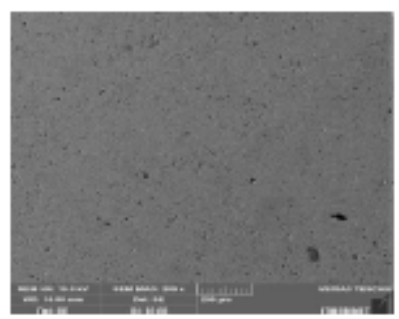

(f) $\mathrm{SH} 1: 200 \mathrm{x}$

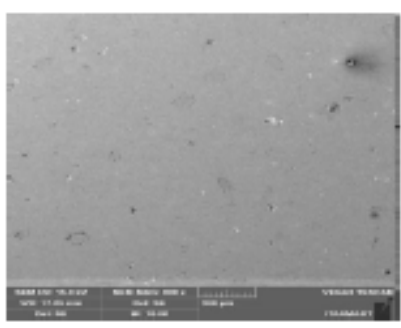

(h) SH2: $200 \mathrm{x}$ 
Micrographs of classes SH, NbC-Ni_967, and WC-Co reference (SEM)

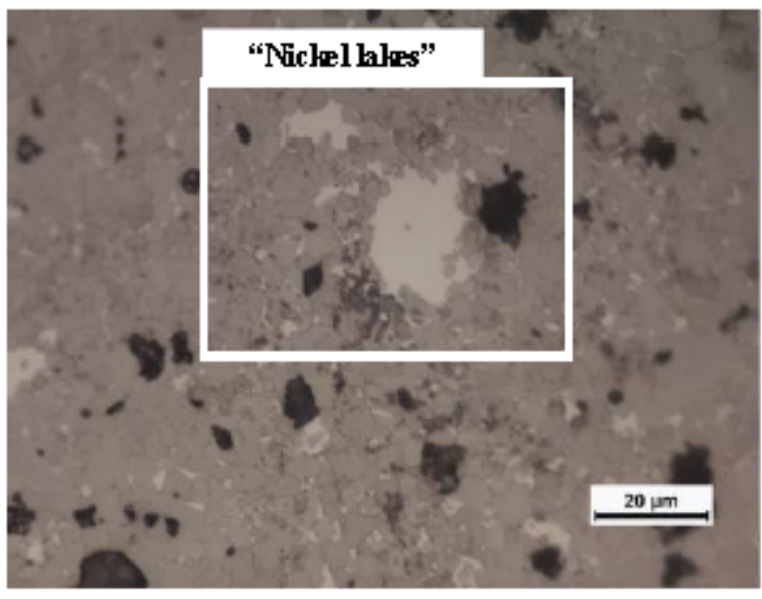

(a) SH1: $1,000 \times(\mathrm{OM})$

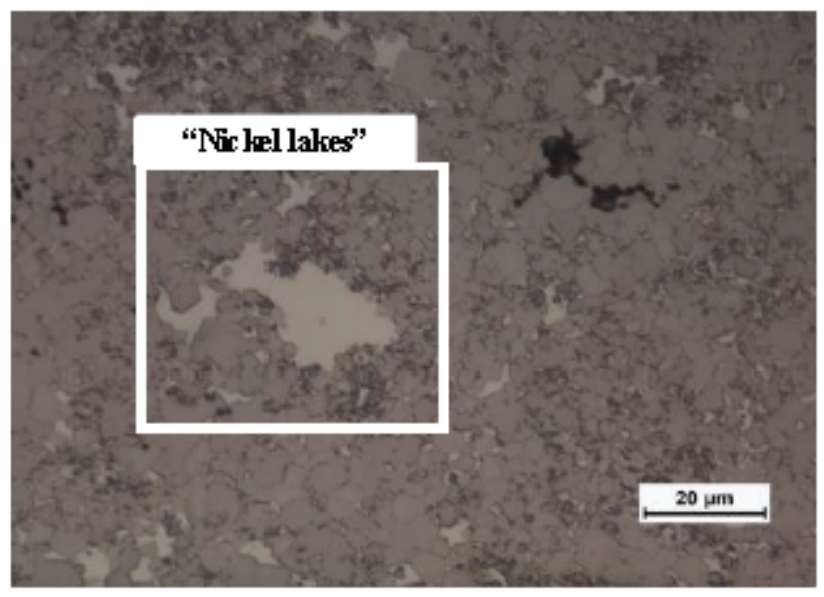

(b) $\mathrm{SH} 2: 1,000 \mathrm{x}(\mathrm{OM})$

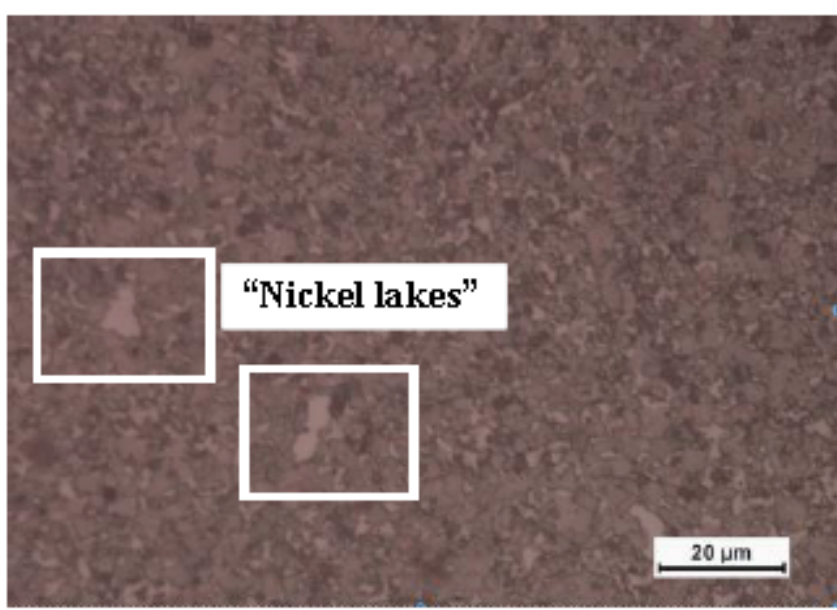

(c) NbC-Ni_967: 1,000x (MO)

\section{Figure 8}

Micrographs of classes SH, and NbC-Ni_967: "Nickel lakes" (OM) 


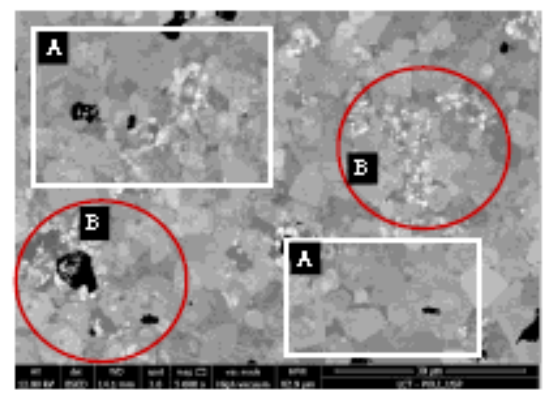

(a) SHl: 5 p00x (SEM)

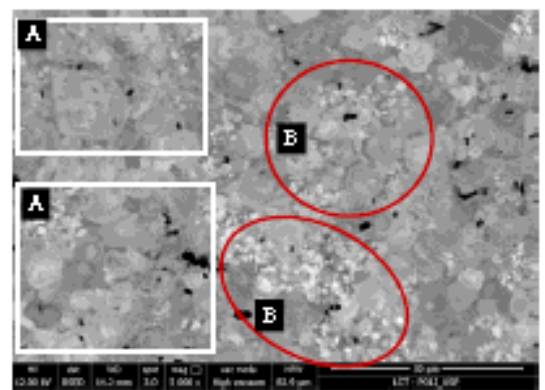

(b) $\mathrm{SH} 2: 5 \rho 00 \times(\mathrm{SEM})$

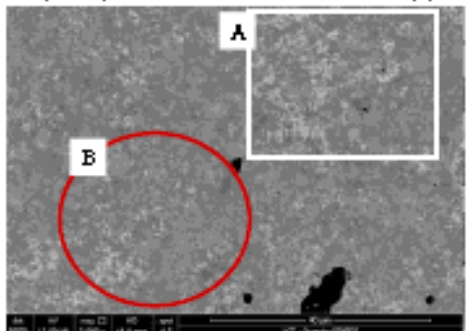

(c) $\mathrm{HbC}-\mathrm{Hi} 967: 5000 \mathrm{x}(\mathrm{SEM})$

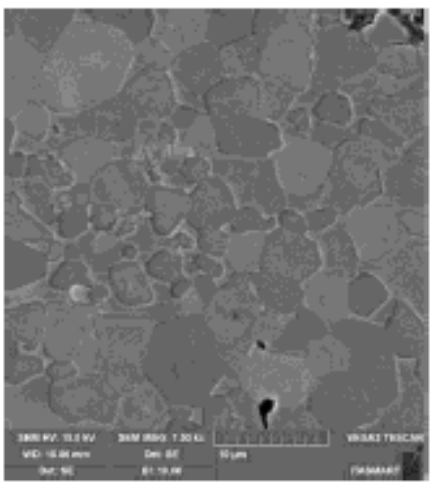

(d) $\mathrm{SHl}: 7,500 \mathrm{x}$ (SEH)

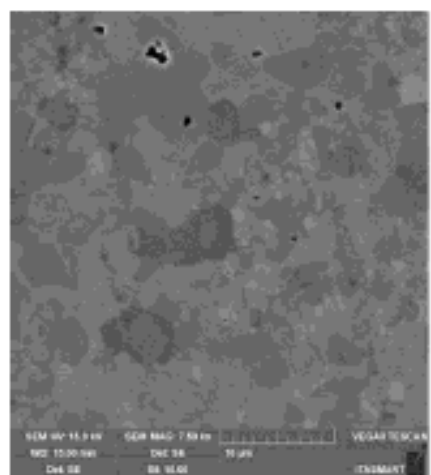

(e) $\mathrm{SH} 2: 7,500 \times(\mathrm{SEM})$

\section{Figure 9}

Micrographs of classes SH, and NbC-Ni_967: microstructure heterogeneity and grain size (SEM)

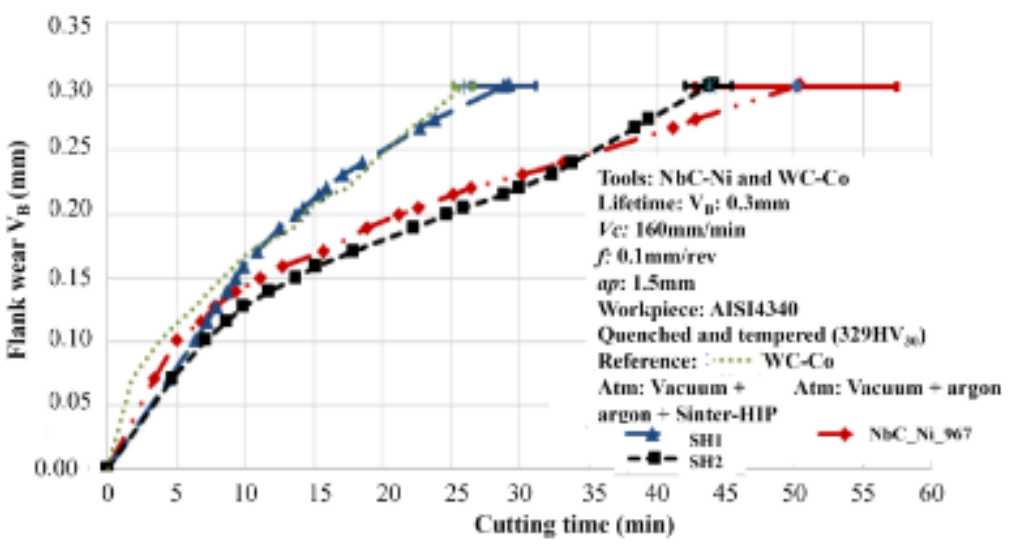

Figure 10

Comparison of average flank wear performance (VB) of class SH cutting tool grades versus reference tool WC-Co and NbC-Ni_967 


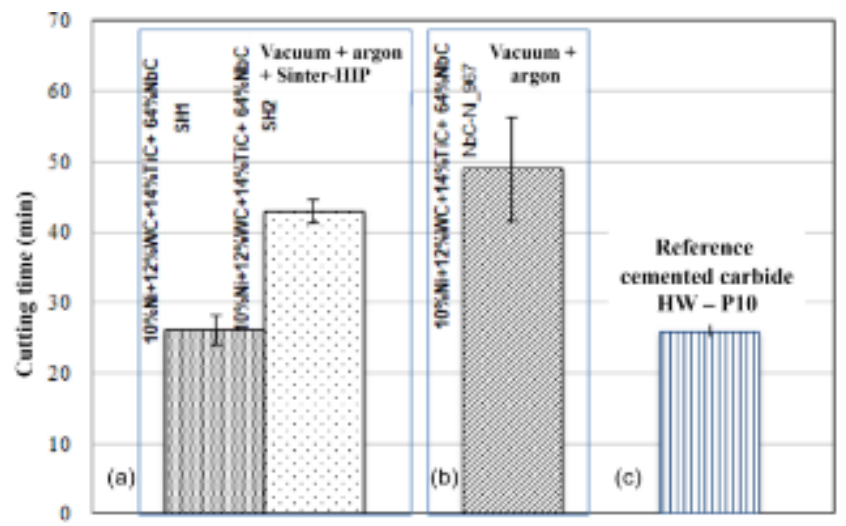

\section{Figure 11}

Lifetime of cutting tools for VB $=0.3 \mathrm{~mm}$ : Classes SH, NbC-Ni_967, and WC-Co reference 


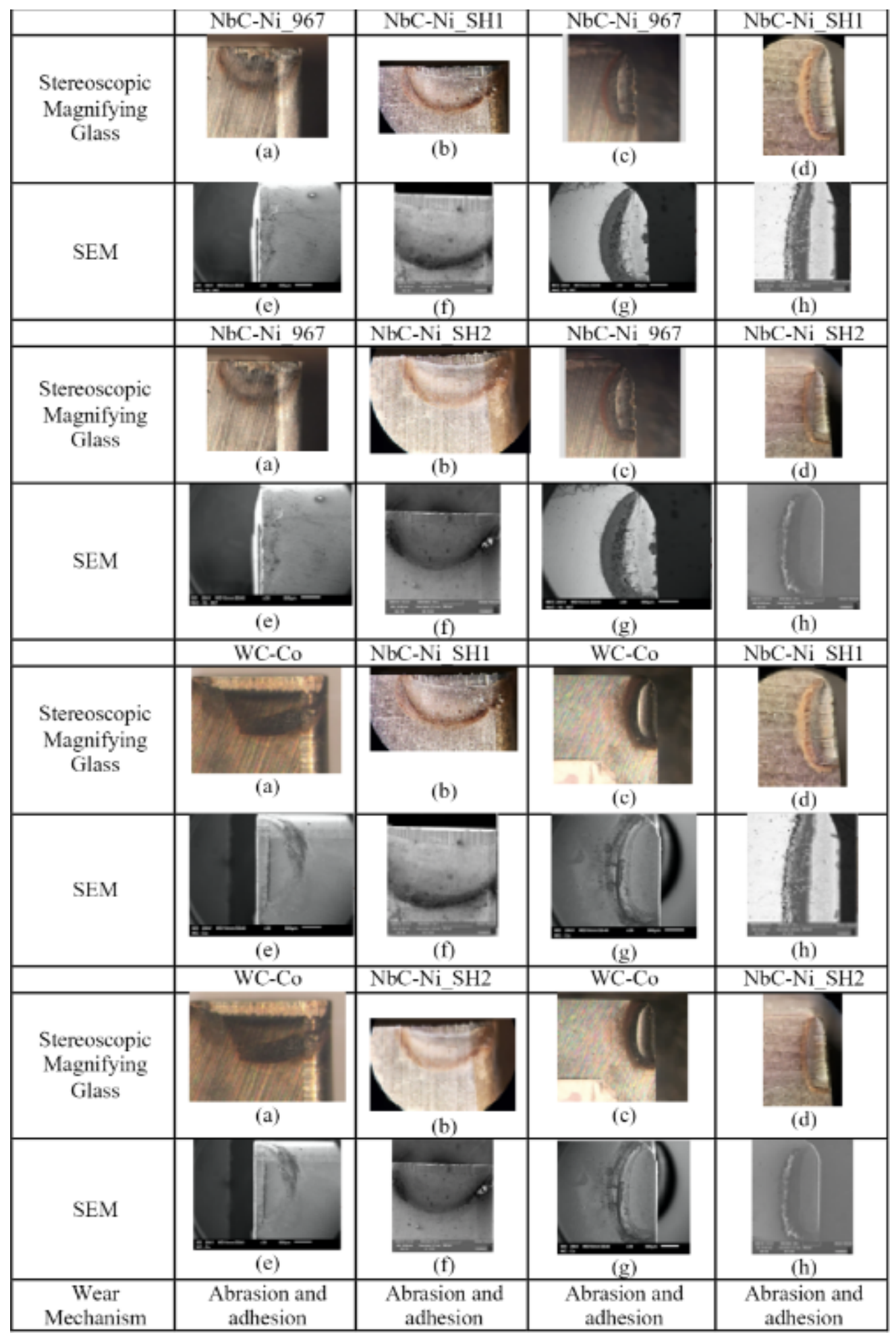

Figure 12

Comparison of wear mechanisms occurred - Abrasion and Adhesion 